\title{
Lipoamide dehydrogenase and diaphorase catalyzed conversion of some NO donors to NO and reduction of NO scavenger 2-phenyl- 4,4,5,5-tetramethylimidazoline-1-oxyl-3-oxide (PTIO)
}

\author{
Alena Stibingerová, Hana Velvarská, Klára Kynčlová, Běla Marounková, Marcela Špundová \\ and Gustav Entlicher
}

Department of Biochemistry, Faculty of Science, Charles University, Hlavova 8, 12840 Prague 2, Czech Republic; E-mail: entg@seznam.cz

\begin{abstract}
One of the key functions of nitric oxide (NO) in human is to dilate blood vessels. We tested glycerol trinitrate (GTN) and other well-known NO donors together with those bearing a $>\mathrm{C}=\mathrm{N}-\mathrm{OH}$ group for possible conversion to NO (or nitrites, respectively) by diaphorase (DP) and lipoamide dehydrogenase (LAD). Both, DP and LAD were unable to convert formamidoxime (FAM), acetone oxime (AC), acetohydroxamic acid (AHA) and $\mathrm{N}^{\omega}$-hydroxy-L-arginine (L-NOHA). On the other hand, we observed good conversion of GTN without the requirement of superoxide anion. However, superoxide anion participated to a varying extent in the conversion of other donors (formaldoxime (FAL), acetaldoxime (AO), nitroprusside (NP), S-nitrosoglutathione (SNOG), S-nitroso-N-acetylpenicillamine (SNAP) and hydroxylamine (HA)). All DP- and LAD-mediated reactions were inhibited by diphenyleneiodonium chloride (DPI), (an inhibitor of flavine enzymes), in a concentration-dependent manner. For these inhibition reactions we determined $K_{i}$ and $\mathrm{IC}_{50}$ values. In addition, we found that conversion of SNOG was significantly accelerated by glutathione reductase (GTR). Like with DP, 2-phenyl-4,4,5,5-tetramethylimidazoline-1-oxyl-3-oxide (PTIO) was reduced also by LAD and thioredoxin reductase (TRR). In summary, we found that LAD significantly accelerates the conversion of a defined subset of NO donors to NO, especially GTN, and eliminates the NO scavenging effect of PTIO.
\end{abstract}

Key words: Lipoamide dehydrogenase - Diaphorase - Glutathione reductase - NO donors - PTIO

\begin{abstract}
Abbreviations: AC, acetone oxime; AHA, acetohydroxamic acid; AO, acetaldoxime; DP, diaphorase from Clostridium kluyveri; DPI, diphenyleneiodonium chloride; ER, resorufin ethyl ether; FAL, formaldoxime hydrochloride; FAM, formamidoxime; GTN, glycerol trinitrate; GTR, glutathione reductase from baker's yeast; HA, hydroxylamine hydrochloride; LAD(i), lipoamide dehydrogenase from bovine intestine; $\mathrm{LAD}(\mathrm{h})$, lipoamide dehydrogenase from pig heart; $\mathrm{MC}$, miconazole nitrate salt; L-NAME, $\mathrm{N}^{\omega}$-nitro-L-arginine methyl ester hydrochloride; L-NOHA, $\mathrm{N}^{\omega}$-hydroxy-L-arginine acetate salt; $\mathrm{NP}$, sodium nitroprusside; PA, proadiphen hydrochloride; PH, phenidone; PTIO, 2-phenyl-4,4,5,5-tetramethylimidazoline-1-oxyl-3-oxide; SNAP, S-nitroso-N-acetylpenicillamine; SNOG, S-nitrosoglutathione; Tris, tris(hydroxymethyl)aminomethane; TRR, thioredoxin reductase from Escherichia coli.
\end{abstract}

\section{Introduction}

In mammals, the main biosynthetic pathway for NO synthesis is the NO-synthase (NOS) catalyzed oxidation of

Correspondence to: Gustav Entlicher, Department of Biochemistry, Faculty of Science, Charles University, Hlavova 8, 12840 Prague 2, Czech Republic

E-mail: entg@seznam.cz
L-arginine to citrulline and NO (Moncada et al. 1991). When overproduced, NO is stored and transported in form of dinitrosyl-iron complexes or S-nitrosothiols in blood and tissues (Alencar et al. 2003). In addition, there are exogenous substances (NO donors) that can produce $\mathrm{NO}$ in biological systems either spontaneously or in enzyme-catalyzed reactions (Feelish 1998; Tullett and Rees 1998). Some of them are used or could potentially be used for treatment of diseases caused by impaired NO production by NOS. Conversion of 
these substances to NO is independent of NOS. Such substances are classified into several groups including organic nitrates (e.g. GTN), organic nitrites (e.g. isoamyl nitrite), inorganic nitroso compounds (e.g. NP), sydnonimines (e.g. molsidomine), S-nitrosothiols (e.g. SNOG) and NONOates $\left(\mathrm{R}^{1} \mathrm{R}^{2} \mathrm{~N}-\left(\mathrm{NO}^{-}\right)-\mathrm{N}=\mathrm{O}\right)$, e.g. DEA/NO (diethylamine dinitric oxide) (Tullet and Rees 1998). In addition, there are many other substances, which can produce NO in biological systems and which can hardly be classified into the above mentioned groups (The Merck Index 1996). Among them there are substances bearing a $>\mathrm{C}=\mathrm{N}-\mathrm{OH}$ group (e.g. oximes). These substances can be metabolized to NO by the cytochrome P-450 system (Jousserandot et al. 1998). The NO donor formaldoxime (FAL) is converted to $\mathrm{NO}$ by $\mathrm{Fe}^{2+}$ and $\mathrm{Fe}^{3+}$ ions, methemoglobin + NADPH + methylene blue, whereas GTN is converted by methemoglobin + NADPH + methylene blue, oxyhemoglobin and oxyhemoglobin + $\mathrm{NADPH}+$ methylene blue (Chalupský et al. 2003). Both, FAL and GTN are also metabolized to NO by DP (Bartík et al. 2004). In addition, GTN is metabolized to NO by mitochondrial aldehyde dehydrogenase (Chen et al. 2002; Ignarro 2002). It seems that mitochondrial aldehyde dehydrogenase 2 is the key enzyme of GTN metabolism (Chen and Stamler 2006; Mayer and Beretta 2008). Finally, some NO donors are thought to be metabolized to NO by hitherto unspecified NAD(P)H-dependent oxidoreductases (Mohazzab et al. 1999; Caro et al. 2001; Souza et al. 2001; Vetrovsky et al. 2002; Ray and Shah 2005).

Here we report a study on the metabolism of different NO donors (GTN, FAL, SNAP, SNOG, NP, AO, FAM, AC, HA, AHA, L-NOHA) to NO by DP and LAD. As already reported, FAL (Fig. 1) and GTN can be metabolized to
NO (confirmed by EPR spectroscopy) by DP (Bartík et al. 2004). Other used substances (FAM, AO, AC, AHA) (Fig. 1) were confirmed as NO donors also by EPR spectroscopy (Chalupský et al. 2004). This enzyme is also capable of reduction of PTIO and elimination of its NO scavenging activity. PTIO is active as NO scavenger in its oxidized form only (Akaike et al. 1993). The capability of LAD and TRR to catalyze the same reaction was also studied.

\section{Materials and Methods}

\section{Chemicals}

Diaphorase from Clostridium kluyveri (DP) (E.C. 1.6.99.1), lipoamide dehydrogenase (E.C. 1.8.1.4) from pig heart $(\mathrm{LAD}(\mathrm{h}))$ and from bovine intestine $(\mathrm{LAD}(\mathrm{i}))$, catalase from bovine liver, superoxide dismutase (SOD) from bovine erythocytes, nitrate reductase from Aspergillus niger, glutathione reductase (GTR) from baker's yeast, thioredoxin reductase (TRR) from E. coli, NADPH, NADH, 2-phenyl4,4,5,5-tetramethylimidazoline-1-oxyl-3-oxide (PTIO), $\mathrm{N}^{\omega}$-nitro-L-arginine methyl ester hydrochloride (L-NAME), diphenyleneiodonium chloride (DPI), proadiphen hydrochloride (PA), resorufin ethyl ether (ER), phenidone (PH), miconazole nitrate salt (MC), $\mathrm{N}^{\omega}$-hydroxy-L-arginine acetate salt (L-NOHA), S-nitrosoglutathione (SNOG), Snitroso-N-acetylpenicillamine (SNAP), formamidoxime (FAM), acetohydroxamic acid (AHA), hydroxylamine hydrochloride (HA), sodium nitroprusside (NP), dimethyl sulfoxide, sulfanilamide, N-(1-naphtyl)ethylenediamine

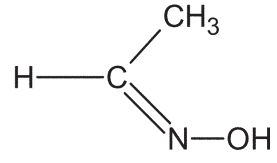

Acetaldoxime (AO)<smiles>CC(=O)NO</smiles>

Acetohydroxamic acid (AHA)<smiles>NC=NO</smiles>

Formamidoxime (FAM)<smiles>ON1CN(O)CN(O)C1</smiles>

Formaldoxime (FAL)

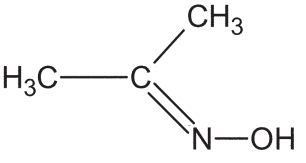

Acetone oxime (AC)

Figure 1. Structures of used oxime derivatives. 
dihydrochloride and Trizma Base (Tris) were purchased from Sigma (USA). Glycerol trinitrate (GTN) 1\% solution in ethanol and acetaldoxime (AO) were products of Merck (Germany), formaldoxime hydrochloride (FAL) and acetone oxime (AC) of Fluka (Switzerland). All other chemicals were products of Lachema (Czech Republic).

\section{Decomposition of tested NO donors to nitrites by DP and} $L A D(h)$ or $L A D(i)$

$\mathrm{DP}(1.7 \mathrm{U} / \mathrm{ml})$ or $\mathrm{LAD}(\mathrm{h})$ or $\mathrm{LAD}(\mathrm{i})(2.9 \mathrm{U} / \mathrm{ml})$ and NADPH or NADH $(1 \mathrm{mmol} / \mathrm{l})$ in $0.05 \mathrm{~mol} / \mathrm{l}$ Tris- $\mathrm{HCl}(\mathrm{pH} 7.6)$ was incubated with substrates at $37^{\circ} \mathrm{C}$ for various time intervals (5-60 min). All concentrations given are final concentrations in the reaction mixture. Final concentrations of substrates are in Table 1. Alternatively, SOD $(200 \mathrm{U} / \mathrm{ml})$ or catalase $(100$ $\mathrm{U} / \mathrm{ml}$ ) was added. Control samples contained substrates and $\mathrm{NADPH}$ or NADH and alternatively SOD or catalase. After incubation nitrites were determined with Griess reagent (Green et al. 1982) and nitrates were determined as nitrites with Griess reagent after reduction with nitrate reductase (Granger et al. 1996). Absorbance of control samples was subtracted from absorbance of samples. Kinetic parameters

Table 1. Final concentrations of NO donors in reaction mixture with $\mathrm{DP}, \mathrm{LAD}(\mathrm{h})$ or $\mathrm{LAD}(\mathrm{i})$

\begin{tabular}{|l|l|r|r|r|r|}
\hline Substance & \multicolumn{5}{|c|}{$[\mathrm{S}](\mathrm{mmol} / \mathrm{l})$} \\
\hline GTN & 0.2 & 0.5 & 1.0 & 1.5 & 2.0 \\
\hline FAL & 2.0 & 3.5 & 5.0 & 7.5 & 10.0 \\
\hline NP & 0.1 & 0.2 & 0.4 & 0.8 & 1.6 \\
\hline SNOG & 0.05 & 0.1 & 0.2 & 0.4 & 0.8 \\
\hline SNAP & 0.1 & 0.2 & 0.4 & 0.8 & 1.6 \\
\hline AO & 0.6 & 1.2 & 2.4 & 4.8 & 9.6 \\
\hline HA & 1.0 & 2.5 & 3.5 & 5.0 & 7.5 \\
\hline FAM & 2.0 & 5.0 & 10.0 & 15.0 & 20.0 \\
\hline AC & 2.0 & 5.0 & 10.0 & 15.0 & 20.0 \\
\hline AHA & 2.0 & 5.0 & 10.0 & 15.0 & 20.0 \\
\hline L-NOHA & 2.0 & 5.0 & 10.0 & 15.0 & 20.0 \\
\hline
\end{tabular}

[S], concentration of substance.
$\left(K_{m}\right.$ and $\left.V_{\max }\right)$ were calculated from the Lineweaver-Burk plot with the use of program Hyperversion 1.1w (http://www. liv.ac.uk/ jse/software.html).

\section{Determination of inhibition constants $\left(K_{i}\right)$ and $I C_{50}$}

$\mathrm{DP}(1.7 \mathrm{U} / \mathrm{ml})$ or LAD $(2.9 \mathrm{U} / \mathrm{ml})$, respectively were incubated in the presence of inhibitors for $60 \mathrm{~min}$ in $0.05 \mathrm{~mol} / \mathrm{l}$ Tris- $\mathrm{HCl}$ buffer ( $\mathrm{pH}$ 7.6). Concentrations of inhibitors and concentrations of NO donors are given in the Table 2 . Aliquots $(0.1 \mathrm{ml})$ of the reaction mixture were removed in 10 min intervals and nitrites were determined by Griess reagent as described above. DPI, MC and ER were dissolved in dimethylsulfoxide at first and then added to the reaction mixture (final concentration of dimethylsulfoxide was 1\%). Samples with equal concentrations of dimethylsulfoxide but without inhibitors served as controls. $K_{i}$ was calculated from the Dixon plot of the reciprocal velocity against inhibitor concentrations. The $\mathrm{IC}_{50}$ values were calculated from $K_{i}$ and $K_{m}$ using Cheng-Prusoff equation $K_{i}=\mathrm{IC}_{50} /(1+$ $\left(\mathrm{S} / K_{m}\right)$ ) where $\mathrm{S}$ is substrate concentration (Cheng and Prusoff 1973). $K_{m}$ and [S] values for IC $_{50}$ calculation were taken from Table 3 and Table 1, respectively.

\section{Reduction of PTIO by DP, $L A D(h)$ and $L A D(i)$ and by TRR}

$\mathrm{DP}(0.016 \mathrm{U} / \mathrm{ml}), \mathrm{LAD}(\mathrm{h})$ or $\mathrm{LAD}(\mathrm{i})(0.027 \mathrm{U} / \mathrm{ml})$ and NADH $(1 \mathrm{mmol} / \mathrm{l})$ or TRR $(0.3 \mathrm{U} / \mathrm{ml})$ and NADPH $(1 \mathrm{mmol} / \mathrm{l})$ in $0.05 \mathrm{~mol} / \mathrm{l}$ Tris- $\mathrm{HCl}$ buffer $(\mathrm{pH} 7.6)$ was incubated with PTIO $(0.15,0.30,0.75,0.90,1.50 \mathrm{mmol} / \mathrm{l})$ at $37^{\circ} \mathrm{C}$ in dark. Alternatively SOD $(200 \mathrm{U} / \mathrm{ml})$ was added. Control samples contained PTIO and NADPH or NADH and alternatively SOD. The reduction of PTIO was determined spectrophotometrically at $550 \mathrm{~nm}$ in time intervals $0,5,10,15,20,25,30$, 40, 50, $60 \mathrm{~min}$. All concentrations given are final concentrations in the reaction mixture.

\section{Results}

We found that with the exception of FAM, AC, AHA and L-NOHA all tested NO donors can be converted by DP

Table 2. Concentrations of inhibitors for determinations of $K_{i}$

\begin{tabular}{|l|c|c|c|c|c|c|}
\hline $\begin{array}{l}\text { Inhibitor } \\
(\mu \mathrm{mol} / \mathrm{l})\end{array}$ & DPI & ER & PH & L-NAME & PA & MC \\
\cline { 2 - 7 } & $10-500$ & $7.5-75$ & $25-250$ & $25-250$ & $25-250$ & $25-250$ \\
\hline
\end{tabular}

Concentrations of NO donors for determinations of $K_{i}$

\begin{tabular}{|l|c|c|c|c|c|c|c|}
\hline \multirow{2}{*}{$\begin{array}{l}\text { NO donor } \\
(\mathrm{mmol} / \mathrm{l})\end{array}$} & GTN & FAL & NP & SNOG & SNAP & AO & HA \\
\cline { 2 - 8 } & 2.0 & 10.0 & 1.0 & 0.5 & 0.5 & 10.0 & 1.0 \\
\hline
\end{tabular}


Table 3. Kinetic parameters for reactions of DP, $L A D(h)$ and $L A D(i)$ with tested NO donors

\begin{tabular}{|l|c|c|c|c|c|c|}
\hline Enzyme & \multicolumn{2}{|c|}{ DP } & \multicolumn{2}{c|}{ LAD $(\mathrm{h})$} & \multicolumn{2}{c|}{ LAD $(\mathrm{i})$} \\
\hline Kinetic parameters & $\begin{array}{c}K_{m} \\
(\mathrm{mmol} / \mathrm{l})\end{array}$ & $\begin{array}{c}V_{\max } \\
(\mu \mathrm{mol} / \mathrm{l} / \mathrm{min})\end{array}$ & $\begin{array}{c}K_{m} \\
(\mathrm{mmol} / \mathrm{l})\end{array}$ & $\begin{array}{c}V_{\max } \\
(\mu \mathrm{mol} / \mathrm{l} / \mathrm{min})\end{array}$ & $\begin{array}{c}K_{m} \\
(\mathrm{mmol} / \mathrm{l})\end{array}$ & $\begin{array}{c}V_{\max } \\
(\mu \mathrm{mol} / \mathrm{l} / \mathrm{min})\end{array}$ \\
\hline GTN & $7.05 \pm 0.71$ & $6.90 \pm 0.62$ & $0.90 \pm 0.08$ & $0.20 \pm 0.03$ & $1.42 \pm 0.13$ & $0.20 \pm 0.03$ \\
\hline FAL & $17.32 \pm 0.82$ & $0.22 \pm 0.02$ & $2.73 \pm 0.12$ & $0.13 \pm 0.01$ & $17.82 \pm 1.43$ & $0.92 \pm 0.13$ \\
\hline NP & $0.07 \pm 0.01$ & $1.38 \pm 0.15$ & $0.84 \pm 0.09$ & $1.03 \pm 0.11$ & $\mathrm{ND}$ & $\mathrm{ND}$ \\
\hline SNOG & $0.32 \pm 0.03$ & $0.30 \pm 0.02$ & $0.12 \pm 0.01$ & $0.62 \pm 0.07$ & $\mathrm{ND}$ & $\mathrm{ND}$ \\
\hline SNAP & $0.92 \pm 0.10$ & $0.84 \pm 0.07$ & $0.42 \pm 0.03$ & $0.51 \pm 0.06$ & $\mathrm{ND}$ & $\mathrm{ND}$ \\
\hline AO & $0.89 \pm 0.07$ & $0.03 \pm 0.01$ & $0.96 \pm 0.08$ & $0.16 \pm 0.01$ & $\mathrm{ND}$ & $\mathrm{ND}$ \\
\hline HA & $0.95 \pm 0.06$ & $0.24 \pm 0.02$ & $3.24 \pm 0.31$ & $0.46 \pm 0.03$ & ND & ND \\
\hline
\end{tabular}

FAM, AC, AHA and L-NOHA were not converted to nitrites by DP or LAD(h). ND, not determined. Results are expressed as mean \pm S.E.M. $(n=4)$.

Table 4. Kinetic parameters for reactions of DP, $\mathrm{LAD}(\mathrm{h})$ and $\mathrm{LAD}(\mathrm{i})$ with tested NO donors in the presence of SOD

\begin{tabular}{|l|c|c|c|c|c|c|}
\hline Enzyme & \multicolumn{2}{|c|}{ DP } & \multicolumn{2}{c|}{ LAD $(\mathrm{h})$} & \multicolumn{2}{c|}{ LAD(i) } \\
\hline Kinetic parameters & $\begin{array}{c}K_{m} \\
(\mathrm{mmol} / \mathrm{l})\end{array}$ & $\begin{array}{c}V_{\max } \\
(\mu \mathrm{mol} / \mathrm{l} / \mathrm{min})\end{array}$ & $\begin{array}{c}K_{m} \\
(\mathrm{mmol} / \mathrm{l})\end{array}$ & $\begin{array}{c}V_{\max } \\
(\mu \mathrm{mol} / \mathrm{l} / \mathrm{min})\end{array}$ & $\begin{array}{c}K_{m} \\
(\mathrm{mmol} / \mathrm{l})\end{array}$ & $\begin{array}{c}V_{\max } \\
(\mu \mathrm{mol} / \mathrm{l} / \mathrm{min})\end{array}$ \\
\hline GTN & $5.75 \pm 0.62$ & $8.34 \pm 0.67$ & $2.27 \pm 0.21$ & $0.26 \pm 0.02$ & $16.93 \pm 1.27$ & $1.38 \pm 0.14$ \\
\hline FAL & $25.03 \pm 0.97$ & $0.10 \pm 0.01$ & $17.18 \pm 1.08$ & $0.69 \pm 0.05$ & $15.83 \pm 0.88$ & $0.29 \pm 0.02$ \\
\hline NP & $0.11 \pm 0.01$ & $1.32 \pm 0.14$ & $2.26 \pm 0.21$ & $0.94 \pm 0.08$ & ND & ND \\
\hline SNOG & $3.66 \pm 0.32$ & $2.92 \pm 0.23$ & $0.44 \pm 0.03$ & $0.41 \pm 0.04$ & $\mathrm{ND}$ & $\mathrm{ND}$ \\
\hline SNAP & $1.13 \pm 0.11$ & $2.09 \pm 0.21$ & $5.48 \pm 0.43$ & $2.09 \pm 0.26$ & $\mathrm{ND}$ & $\mathrm{ND}$ \\
\hline AO & no reaction & no reaction & no reaction & no reaction & ND & ND \\
\hline HA & $10.55 \pm 0.92$ & $0.06 \pm 0.01$ & no reaction & no reaction & ND & ND \\
\hline
\end{tabular}

FAM, AC, AHA and L-NOHA were not converted to nitrites by DP or LAD(h) in the presence of SOD. ND, not determined. Results are expressed as mean \pm S.E.M. $(n=4)$.

(a microbial NAD $(\mathrm{P}) \mathrm{H}$ oxidase) and LAD $(\mathrm{NAD}(\mathrm{P}) \mathrm{H}$ oxidase of mammalian origin) to NO (or nitrites, respectively) (Table 3). The reactions are affected to different extent by simultaneously produced superoxide ion. This effect is most apparent with AO, where conversion is completely dependent on the formation of the superoxide ion (Tables 3 and 4). Addition of catalase had no effect on the reactions. For GTN and FAL effect of $\operatorname{LAD}(\mathrm{h})$ and $\mathrm{LAD}(\mathrm{i})$ was compared (Tables 3 and 4). Tested donors are better converted to NO by $\operatorname{LAD}(\mathrm{h})$ than by $\mathrm{LAD}(\mathrm{i})$. Conversion of SNOG to NO was accelerated also by GTR in a concentration-dependent manner $\left(K_{m}=3.3 \pm 0.3 \mathrm{mmol} / \mathrm{l}, V_{\max }=4.0 \pm 0.4 \mu \mathrm{mol} / \mathrm{l} /\right.$ $\mathrm{min}, 10 \mathrm{U} / \mathrm{ml})$ and $\left(K_{m}=0.60 \pm 0.05 \mathrm{mmol} / \mathrm{l}, V_{\max }=1.5 \pm\right.$ $0.2 \mu \mathrm{mol} / \mathrm{l} / \mathrm{min}, 20 \mathrm{U} / \mathrm{ml})$. We further found that in addition to DP, PTIO was reduced by $\operatorname{LAD}(\mathrm{h}), \mathrm{LAD}(\mathrm{i})$ and by TRR (Table 5). Addition of SOD to the reaction mixture had no effect on the reduction of PTIO (data not shown) and GTR did not reduce PTIO. All reactions of DP, $\mathrm{LAD}(\mathrm{h})$ or $\mathrm{LAD}(\mathrm{i})$ could be abolished by heating to $100^{\circ} \mathrm{C}$ for $5 \mathrm{~min}$.
We tested the inhibitors DPI, ER, PH, L-NAME, PA and MC. Only DPI inhibited all DP- and LAD(h)-dependent reactions in a concentration-dependent manner (Table 6). ER inhibited reactions of DP and LAD(h) with GTN only with about 7-20\% efficiency. Since ER has a high absorbance at $540 \mathrm{~nm}$, its $K_{i}$ and $\mathrm{IC}_{50}$ could not be determined. $\mathrm{PH}$ and $\mathrm{MC}$ inhibited only reactions of DP and $\mathrm{LAD}(\mathrm{h})$ with NP in a concentration independent manner. Furthermore, we

Table 5. Kinetic parameters of reactions of DP, LAD(h), LAD(i) and TRR with PTIO

\begin{tabular}{|l|c|c|}
\hline Enzyme & $K_{m}(\mathrm{mmol} / \mathrm{l})$ & $V_{\max }(\mu \mathrm{mol} / 1 / \mathrm{min})$ \\
\hline $\mathrm{DP}$ & $1.72 \pm 0.16$ & $1.68 \pm 0.12$ \\
\hline $\mathrm{LAD}(\mathrm{h})$ & $1.45 \pm 0.15$ & $4.64 \pm 0.19$ \\
\hline LAD $(\mathrm{i})$ & $0.46 \pm 0.08$ & $0.32 \pm 0.04$ \\
\hline TRR & $3.29 \pm 0.12$ & $0.64 \pm 0.07$ \\
\hline
\end{tabular}

Results are expressed as mean \pm S.E.M. $(n=5)$. 
Table 6. Inhibition of DP and LAD(h) reaction with NO donors by DPI

\begin{tabular}{|l|c|c|c|c|}
\hline Enzyme & \multicolumn{2}{|c|}{ DP } & \multicolumn{2}{c|}{ LAD $(\mathrm{h})$} \\
\hline Parameters & $K_{i}(\mathrm{mmol} / \mathrm{l})$ & $\mathrm{IC}_{50}(\mathrm{mmol} / \mathrm{l})$ & $K_{i}(\mathrm{mmol} / \mathrm{l})$ & $\mathrm{IC}_{50}\left(\mathrm{mmol}^{\prime} \mathrm{l}\right)$ \\
\hline GTN & $0.12 \pm 0.01$ & $0.15 \pm 0.02$ & $0.60 \pm 0.07$ & $1.93 \pm 0.37$ \\
\hline FAL & $0.27 \pm 0.03$ & $0.43 \pm 0.06$ & $0.56 \pm 0.06$ & $2.61 \pm 0.38$ \\
\hline NP & $0.22 \pm 0.02$ & $3.36 \pm 0.90$ & $0.31 \pm 0.03$ & $0.68 \pm 0.11$ \\
\hline SNOG & $0.53 \pm 0.05$ & $1.36 \pm 0.23$ & $0.35 \pm 0.03$ & $1.81 \pm 0.19$ \\
\hline SNAP & $0.39 \pm 0.03$ & $0.60 \pm 0.08$ & $0.80 \pm 0.09$ & $1.75 \pm 0.29$ \\
\hline HA & $0.45 \pm 0.09$ & $5.51 \pm 0.96$ & $0.29 \pm 0.03$ & $3.31 \pm 0.64$ \\
\hline
\end{tabular}

For $K_{i}$ results are expressed as mean \pm S.E.M. $(n=4)$.

found that $\mathrm{PH}$ significantly increased the decomposition of SNAP in the presence of NADH. This reaction was not influenced by DP or LAD(h).

Finally, we measured the nitrite/nitrate ratio resulting from the reactions catalyzed by $\mathrm{DP}$ and $\mathrm{LAD}(\mathrm{h})$. This ratio varied from 52/48 for reaction of $\mathrm{LAD}(\mathrm{h})$ with FAL to 91/9 for reactions of either DP or $\mathrm{LAD}(\mathrm{h})$ with NP. In all cases, the amount of nitrites formed was larger than that of nitrates. Mostly this difference was very pronounced.

\section{Discussion}

A number of NO donors are known since a long time. These substances can produce NO either spontaneously or under the enzymic catalysis. L-NOHA and HA were found to be converted to NO by superoxide anion (Vetrovsky et al. 1996). However, not until 2002 the first enzyme was described that catalyzes conversion of GTN to NO (Chen et al. 2002; Ignarro 2002). Later on it was shown that NO donors could be metabolized by Fe ions, superoxide, methemoglobin, and oxyhemoglobin (Chalupský et al. 2003). Finally, DPdependent NO production from GTN and FAL was also reported (Bartík et al. 2004), albeit with an enzyme of bacterial origin. Therefore we tested enzymic activities of LAD, which is a similar enzyme of animal origin and compared it with DP activity. It is clear that both enzymes are in many aspects similar.

Two groups of NO donors were chosen. Substances known as NO donors for a long time and the new group of substances bearing $>\mathrm{C}=\mathrm{N}-\mathrm{OH}$ group that were shown to relax aorta rings and to produce NO by EPR spectroscopy (Chalupský et al. 2004). These substances were chosen due to their structural similarity with L-NOHA, intermediate in the NOS catalyzed conversion of arginine to NO. Nonenzymic conversion of studied NO donors (except SNAP and, especially SNOG) was very low as judged according to control experiments (NO donors + NADPH or NADH).
However, non-enzymic decomposition of SNAP and SNOG is well-known fact. Analyses of reactions catalyzed by DP as well as by LAD are complicated by their simultaneous $\mathrm{NAD}(\mathrm{P}) \mathrm{H}$ oxidase activity. This activity somewhat lowers the effective concentration of $\mathrm{NAD}(\mathrm{P}) \mathrm{H}$ during reaction course by about $25 \%$ (results not shown) and produces superoxide. Therefore all kinetic data were measured also in the presence of SOD. NAD $(\mathrm{P}) \mathrm{H}$ oxidase activity of $\mathrm{DP}$ was found even after its purification by dialysis (data not shown), which has not been observed by other groups (Kaplan et al. 1969; Bhushman et al. 2002).

Table 3 shows that some NO donors are better converted to $\mathrm{NO}$ by $\mathrm{LAD}(\mathrm{h})$ than by $\mathrm{DP}$ and vice versa. Superoxide ion participates in such conversion reactions to different extent (Table 4). Superoxide ion had a very small effect on conversion of GTN, irrespective of the conversion by DP or $\mathrm{LAD}(\mathrm{h})$. Comparison of LAD from different tissues (LAD $(\mathrm{h})$ - from heart; $\mathrm{LAD}(\mathrm{i})$ - from intestine) showed (Table 3 and 4) that tested donors are better converted to NO by LAD $(\mathrm{h})$ than by $\mathrm{LAD}(\mathrm{i})$.

SNOG is one of the long-known donors that were tested in this study. According to the literature SNOG should not be a substrate of GTR and therefore this enzyme should not contribute to the conversion of SNOG to NO (Becker et al. 1995). In contrast, our results clearly show that SNOG is a good substrate of GTR and that GTR can significantly contribute to its conversion to NO. We further found that its reaction kinetics strongly depends on the concentration of the enzyme and that GTR is a very substrate specific.

It was reported that $\mathrm{LAD}(\mathrm{h})$ can catalyze $\mathrm{NADH}$-dependent scavenging of NO (Igamberdiev et al. 2004). As a result of this reaction nitrates were formed. This reaction needs NADH as a cofactor, NADPH is ineffective. It has pH optimum at 6.0. In our experiments we did not observe this reaction. Reactions of $\mathrm{DP}, \mathrm{LAD}(\mathrm{h})$ and $\mathrm{LAD}(\mathrm{i})$ with substrates were carried out at $\mathrm{pH} 7.6$, both cofactors, $\mathrm{NADH}$ and NADPH were equally effective and mostly nitrites were formed. 
As DP and LAD are flavine-containing enzymes there is not very surprising that their reactions with all substrates were inhibited with DPI (inhibitor of flavine enzymes) in a concentration-dependent manner. In the case of a few other inhibitors some inhibition was observed, too. However, kinetic parameters of these inhibitions could not be regularly determined either due to erratic inhibition behaviour or a high absorbance of some inhibitors at $540 \mathrm{~nm}$ (used for determination of nitrites). In case of SNAP, $\mathrm{PH}$ even accelerated the decomposition of this substance to NO.

DP has been reported to reduce PTIO (Bartík et al. 2004). Our results show that PTIO can be reduced also by $\operatorname{LAD}(\mathrm{h})$ and $L A D(i)$ and TRR. The reduction of PTIO is best catalyzed by $\mathrm{LAD}(\mathrm{h})$ and $\mathrm{LAD}(\mathrm{i})$.

With the exception of GTN, the tested NO donors are not very good substrates of $\mathrm{DP}, \mathrm{LAD}(\mathrm{h})$ or $\mathrm{LAD}(\mathrm{i})$. Superoxide anion participates on the conversion of these donors to NO to a varying extent. It is apparent that all superoxide anion producing enzyme systems and some other enzymes participate in the metabolism of all tested NO donors. Mitochondrial aldehyde dehydrogenase was identified as such enzyme for GTN (Chen et al. 2002; Ignarro 2002). It is interesting that some NO donors for which the formation of NO in the aortic tissue was shown by EPR spectroscopy (FAL, FAM, AHA) (Chalupský et al. 2004) were not converted at all to NO by $\mathrm{DP}, \mathrm{LAD}(\mathrm{h})$ and $\mathrm{LAD}$ (i) (FAM, AHA) or were relatively bad substrates of these enzymes (FAL). In spite of these findings the above-described substances decreased blood pressure of experimental animals (rats) after intravenous application (Jaroš et al. 2007). However, LAD could participate in metabolism of some important NO donors, especially GTN, in spite of the fact that $K_{m}$ values for transformation of GTN are much higher than those obtained with aldehyde dehydrogenase. LAD could also metabolize some NO donors by means of superoxide anion which is formed due to $\mathrm{NAD}(\mathrm{P}) \mathrm{H}$ oxidase activity of this enzyme.

\section{References}

Akaike T., Yoshida M., Miyamoto Y., Sato K., Kohno M., Sasamoto K., Miyazaki K., Ueda S., Maeda H. (1993): Antagonistic action of imidazolineoxyl $\mathrm{N}$-oxides against endotheliumderived relaxing factor/NO through a radical reaction. Biochemistry 32, 827-832; doi:10.1021/bi00054a013

Alencar J. L., Chalupský K., Sarr M., Schini-Kerth V., Vanin A. F., Stoclet J.-C., Muller B. (2003): Inhibition of arterial contraction by dinitrosyl-iron complexes: critical role of the thiol ligand in determining rate of nitric oxide (NO) release and formation of releasable NO stores by S-nitrosation. Biochem. Pharmacol. 66, 2365-2374; doi:10.1016/j.bcp.2003.07.017

Bartík P., Chalupský K., Vavruška, L., Muller B., Stoclet J.-C., Entlicher G. (2004): Diaphorase can metabolize some vasorelaxants to $\mathrm{NO}$ and eliminate $\mathrm{NO}$ scavenging effect of 2-phenyl-4,4,5,5,-tetramethylimidazoline-1-oxyl-3oxide (PTIO). Physiol. Res. 53, 615-620

Becker K., Gui M., Schirmer R. H. (1995): Inhibition of human glutathione reductase by S-nitrosoglutathione. Eur. J. Biochem. 234, 472-478; doi:10.1111/j.14321033.1995.472_b.x

Bhushan B., Halasz A., Spain J. C., Hawari J. (2002): Diaphorase catalyzed bio-transformation of RDX via $\mathrm{N}$-denitration mechanism. Biochem. Biophys. Res. Commun. 296, 779-784; doi:10.1016/S0006-291X(02)00874-4

Caro A. A., Cederbaum A. I., Stoyanovsky D. A. (2001): Oxidation of the ketoxime acetoxime to nitric oxide by oxygen radiacal-generating systems. Nitric Oxide 5, 413-424; doi:10.1006/niox.2001.0362

Chalupský K., Bartík P., Eklová S., Entlicher G. (2003): Possible metabolic pathways of conversion of formaldoxime and glyceryl trinitrate to NO. Gen. Physiol. Biophys. 22, 233-242

Chalupský K., Lobysheva I., Nepveu F., Gadea I., Beranová P., Entlicher G., Stoclet J.-C., Muller B. (2004): Relaxant effect of oxime derivatives in isolated rat aorta: role of nitric oxide (NO) formation in smooth muscle. Biochem. Pharmacol. 67, 1203-1214; doi:10.1016/j.bcp.2003.11.012

Chen Z., Zhang J., Stamler J. S. (2002): Identification of the enzymatic mechanism of nitroglycerin bioactivation. Proc. Natl. Acad. Sci. U.S.A. 99, 8306-8311; doi:10.1073/ pnas. 122225199

Chen Z., Stamler J. S. (2006): Bioactivation of nitroglycerin by the mitochondrial aldehyde dehydrogenase. Trends Cardiovasc. Med. 16, 259-265; doi:10.1016/ j.tcm.2006.05.001

Cheng Y., Prusoff W. H. (1973): Relationship between inhibition constant $(\mathrm{Ki})$ and concentration of inhibitor which causes 50 per cent inhibition (I50) of an enzymatic reaction. Biochem. Pharmacol. 22, 3099-3108; doi:10.1016/00062952(73)90196-2

Feelish M. (1998): The use of nitric oxide donors in pharmacological studies. Naunyn-Schmiedeberg's Arch. Pharmacol. 358, 113-122; doi:10.1007/PL00005231

Granger D. L., Taintor R. R., Boockvar K. S., Hibbs J. B. Jr. (1996): Measurement of nitrate and nitrite in biological samples using reductase and Griess reaction. Methods Enzymol. 268, 142-151; doi:10.1016/S0076-6879(96)68016-1

Green L., Wagner D., Glogowski J., Skipper P. L., Wishnok J. S., Tannenbau S. R. (1982): Analysis of nitrate, nitrite and $(15 \mathrm{~N})$ nitrate in biological fluids. Anal. Biochem. 126, 131-138; doi:10.1016/0003-2697(82)90118-X

Igamberdiev A. U., Bykova N. V., Ens W., Hill R. D. (2004): Dihydrolipoamide dehydrogenase from porcine heart catalyzes NADH-dependent scavenging of nitric oxide. FEBS Lett. 568, 146-150; doi:10.1016/j.febslet.2004.05.024

Ignarro L. J. (2002): After 130 years, the molecular mechanism of action of nitroglycerin is revealed. Proc. Natl. Acad. Sci. U.S.A. 99, 7816-7817; doi:10.1073/pnas.132271799

Jaroš F., Straka T., Dobešová Z., Pintérová M., Chalupský K., Kuneš J., Entlicher G., Zicha J. (2007): Vasorelaxant activity of some oxime derivatives. Eur. J. Pharmacol. 575, 122-126; doi:10.1016/j.ejphar.2007.07.040 
Jousserandot A., Boucher J.- L., Henry Y., Niklaus B., Clement B., Mansuy D. (1998): Microsomal cytochrome P450 dependent oxidation of $\mathrm{N}$-hydroxy-guanidines, amidoximes, and ketoximes: mechanism of the oxidative cleavage of their $\mathrm{C}=\mathrm{N}(\mathrm{OH})$ bond with formation of nitrogen oxides. Biochemistry 37, 17179-17191; doi:10.1021/bi981175c

Kaplan F., Setlow P., Kaplan N. O. (1969): Purification and properties of a DPNH-TPNH diaphorase from Clostridium kluyverii. Arch. Biochem. Biophys. 132, 91-98; doi:10.1016/0003-9861(69)90340-3

Mayer B., Beretta M. (2008): The enigma of nitroglycerin bioactivation and nitrate tolerance: news, views and troubeles. Br. J. Pharmacol. 155, 170-184; doi:10.1038/bjp.2008.263

Mohazzab-H K. M., Kaminski P. M., Agarwal R., Wolin M. S. (1999): Potential role of a membrane-bound NADH oxidoreductase in nitric oxide release and arterial relaxation to nitroprusside. Circ. Res. 84, 220-228

Moncada S., Palmer R. M. J., Higgs E. A. (1991): Nitric oxide: physiology, pathophysiology, and pharmacology. Pharmacol. Rev. 43, 109-142

Ray R., Shah A.M. (2005): NADPH oxidase and endothelial cell function. Clin. Sci. 109, 217-226; doi:10.1042/ CS20050067

Souza H. P., Laurindo F. R. M., Ziegelstein R. C., Berlowitz C. O., Zweier J. L. (2001): Vascular NAD(P)H oxidase is distinct from the phagocytic enzyme and modulates vascular reactivity control. Am. J. Physiol. Heart Circ. Physiol. 280, H658-667

The Merck Index (1996): An encyclopedia of chemicals, drugs and biologicals. (Ed. S. Budavari), Merck research laboratories division of Merck\&Co., Whitehouse Station, NJ, USA, pp. Ther-27-28

Tullet J. M., Rees D. D. (1998): Use of NO donors in biological systems. In: Methods in Molecular Biology. Vol. 100. Nitric oxide protocols. (Ed. Titheradge M. A.), pp. 205-214, Humana Press, Totowa, NJ, USA

Vetrovsky P., Stoclet J.-C., Entlicher G. (1996): Possible mechanism of nitric oxide production from NG-hydroxy-L-arginine or hydroxylamine by superoxide ion. Int. J. Biochem. Cell Biol. 28, 1311-1318; doi:10.1016/S1357-2725(96)00089-1

Vetrovsky P., Boucher J.-L., Schott C., Beranova P., Chalupsky K., Callizot N., Muller B., Entlicher G., Mansuy D., Stoclet J.-C. (2002): Involvement of NO in the endotheliumindependent relaxing effects of $\mathrm{N} \omega$-hydroxy-L-arginine and other compounds bearing a $\mathrm{C}=\mathrm{NOH}$ function in the rat aorta. J. Pharmacol. Exp. Ther. 303, 823-830; doi:10.1124/jpet.102.038612

Received: October 7, 2008

Final version accepted: September 16, 2009 